\title{
DICTÁMENES EN TORNO A LAS CONJETURAS DONOSIANAS ${ }^{1}$
}

\author{
Dictations on the conjectures made by José Donoso \\ Rodrigo Cánovas*
}

\section{RESUMEN}

Este artículo es una lectura de Conjeturas sobre la memoria de mi tribu, del escritor José Donoso, atendiendo a los procedimientos retóricos y modos culturales que le permiten alterar la memoria oficial de una familia chilena. Donoso restituye una genealogía familiar, llenando sus vacíos y censuras a través de conjeturas, que le abren la posibilidad de dialogar de un modo personal con iconos culturales relevantes para su creación literaria (Sigmund Freud, Marcel Proust, Jorge Luis Borges), y a la vez, de comentar alegóricamente la historia política y cultural chilena. En breve, él hace conjeturas sobre su historia personal, que es también un emblema de la nación.

Palabras clave: Memorias, genealogías, José Donoso, Literatura Chilena.

\begin{abstract}
This article presents Conjeturas sobre la memoria de mi tribu, a memoir written by the Chilean writer José Donoso, emphasizing the rethorical and cultural modes that allows him to alter the official records and memories of a Chilean family. Donoso reshapes a

${ }^{1}$ Artículo realizado en el marco del proyecto $\mathrm{N}^{\circ} 1130002$ del Fondo Nacional de Desarrollo Científico y Tecnológico (Fondecyt) titulado "Relatos (auto)biográficos chilenos (1991-2011): Nuevas y antiguas señas de identidad".

* Facultad de Letras, Pontificia Universidad Católica de Chile. Santiago, Chile. Correo electrónico: rcanovas@uc.cl
\end{abstract}

Artículo recibido el 31 de enero de 2014. Aceptado el 26 de agosto de 2014. 
familiar genealogy in order to fill in its gaps and censorships through conjectures. In this way he opens a space to get a personal contact with cultural icons relevant for his writting (such as Sigmund Freud, Marcel Proust and Jorge Luis Borges), and to make allegorical comments about the political and cultural life. In brief, he constructs conjectures about his autobiography, which also constitutes itself a national emblem.

Keywords: Memoirs, genealogies, José Donoso, Chilean Literature.

Enfermo, con pocas fuerzas, algo ya ido, él mismo convertido en una conjetura, José Donoso se lanza a escribir una historia familiar como último sostén. "Ahora he cumplido setenta años y cuento con lirios y nostalgia para dar y regalar; estoy seguro de que me ha llegado el momento de revisar y revalorar -reinventándola- mi propia historia y la de los míos, y aceptar todo lo que ella puede tener, y de hecho tiene, de 'trucada' "(15).

Al leer esta historia, sorprende la parquedad y la escasa intimidad autobiográfica que hay en ella: recuerdos muy panorámicos sobre la infancia -a los doce años, su sensación de ser "un pelele, un ser lamentablemente incompleto" (67)-, apuntes desvaídos sobre las dos casas donde vivió (la preciada de la calle Holanda y la de las tías viejas en Ejército), avatares menores de colegio y versiones periodísticas corregidas sobre sus viajes a Punta Arenas y a Buenos Aires, cuando adolescente. Se tiene incluso la sensación que Donoso pierde la oportunidad de elaborar con mayor profundidad algunos tópicos preciados, como su sentimiento de inferioridad social: "dar testimonio de un pequeño sufrimiento infantil, el del niño burgués, que no se calma con una hogaza ni con un chaleco" (117-118); o su deprimente relación con su padre 2 . Uno siente que este texto se comporta como corriendo (y no descorriendo) un tupido velo sobre otra escritura -por ejemplo, la de sus Diarios de escritor e incluso, la de sus obras literarias magnas-, por la escasa intensidad grotesca de sus figuraciones.

Es posible que estas consideraciones sean injustas; por cuanto el interés de Pepe es reconstituir una genealogía, un escudo de armas que -tiene plena fe- lo sustente en el tiempo, lo sustraiga a la muerte. Obsesivo genealogista, consulta archivos coloniales (especula que el primer Donoso es hijo de un cura), visita la antigua casa talquina de su familia (todavía en pie y convertida en ruinoso edificio, que aloja oficinas públicas), recorre la región de Extremadura, probable lugar de proveniencia de sus ancestros y juega con los inciertos datos de una memoria familiar (y nacional) difusa para situarlos en la historia política al parecer, durante

2 Tópicos sí trabajados con más ímpetu por Jorge Edwards en Los círculos morados. Memorias I, de 2012: el impacto de su pertenencia a la rama venida a menos de una familia pudiente (y simultáneamente, la conciencia de ser un Edwards en el concierto social chileno); el nulo reconocimiento paterno hacia sus inclinaciones literarias, la devastadora distancia afectiva. 
la Independencia, muchos pertenecieron al bando realista y más tarde se reparten entre liberales y conservadores. Hombre antiguo, se esmera por alinear a los Donoso junto a los ilustres de la nación desde su fundación (la bisabuela le debe su riqueza a su tío el Obispo Cienfuegos, que firmó el Acta de la Independencia) y deja en claro su poderío político local al iluminar el centro de todo el relato con la foto familiar del banquete ofrecido en la casa talquina por la bisabuela María en 1888 al político don Federico Errázuriz Echaurren, luego presidente de la nación.

Ahora bien, por sobre los blasones, lo que le importa a Pepe es el orden que los sustentan, legible en una memoria hecha con el material de un tupido velo, forma chilena "para ocultar lo molesto, lo vergonzoso, lo peligroso y, en último término, la verdad" (167). Con un lenguaje más bien provinciano, que esconde el humor negro, se aclara: "Este 'tupido velo' es aceptado como un remedio casero, siempre a la mano, como las aspirinas para las friegas, sin los cuales sería imposible vivir" (167). Por ello, frente a una historia roma y una memoria esquiva, llena de recovecos, solo queda el truco, la conjetura, que permiten el surgimiento de las versiones obliteradas, cuyos signos pueden entreverse en el espacio chileno (rumores, consejas, fotos guardadas, borrones, el habla demencial de las viejas donosianas, la arquitectura colonial, la conversación diaria) y cuya posible réplica es este libro.

En las páginas siguientes intentaremos un breve diseńo de esta escritura memoriosa, dando privilegio a los procedimientos que le permiten a su autor (el personaje-autor, la autoría) inscribirse como un nombre en este árbol, para que así se pueda colgar de él -es su deseo- su progenie.

\section{TRIBU, SU MEMORIA CONJETURAL}

La voz de la tribu, su persistencia, que se erige como sustento de una comunidad: ése es uno de los ejes de este libro, en el cual la fugaz figura del Yo pretende perpetuarse en una escritura de sabor antiguo.

El título del libro -Conjeturas sobre la memoria de mi tribu- marca las entradas de lectura y también su íntima interconexión: memoria tribal, memoria conjetural, escritura yoica jugando a disolverse en los orígenes.

Mi tribu. Desde el capítulo inaugural el autor la identifica con el apellido paterno: "Mi padre pertenece a una vieja raza de latifundistas originada en la Conquista, de la que yo encarno la decimoquinta generación en línea recta desde el primer Donoso llegado a Chile en 1581" (21). Aparece así inserto -en línea recta- en uno de los clanes campestres que funda la tierra primitiva americana: "los Donoso, mi adhesión a esta tierra primitiva" (162).

En su acepción histórica se denomina tribu a las agrupaciones en que se dividían algunos pueblos antiguos; así, por ejemplo, se hace referencia a las 
doce tribus del pueblo hebreo y a las tres de los romanos. Al referirse, entonces, Pepe Donoso a los suyos como tribu, los sitúa como depositarios naturales del fundamento de una cultura y a él como el bardo que recoge una memoria hecha de gajos y remiendos.

La memoria de mi tribu. Desde esta perspectiva de una genealogía fundante, el ejercicio literario es entendido como la recreación de un archivo que se mantenga en el tiempo: "pienso que debajo de toda pasión literaria transcurre una oscura pasión por rescatar, salvar, conservar, preservar algo que alguien, en un futuro muy lejano, puede recibir y recoger como un mensaje enviado desde este lado del mundo" (99-100).

Será, sin embargo, una escritura hecha con fragmentos, con series inacabadas, pero que logran delinear destinos antiguos, como los cantos homéricos: "Porque, ¿qué otra cosa es, al fin y al cabo, La Ilíada, sino el contenido de un morral repleto con los desechos de la memoria de un bardo itinerante, que al caminar por los cerros y los campamentos de Jonia reunió en fragorosos cantos los fragmentos de la memoria de su tribu, y las astillas de memoria que otros bardos fueron depositando allí?" (100).

Al bardo de Jonia le corresponde el bardo americano, cuya tarea es recolectar las materias del pasado en un relato recreado como una foto en sepia, donde aparezcan los usos y costumbres de los Donoso en sus tierras talquinas: "Soy del ciclo americano, de La Araucana, de El cautiverio feliz, de mil historias nuestras. Somos una familia vieja en Chile, lo que no significa aristocrática, porque en nuestro país todos, oligarcas, clase media, pueblo, estamos más o menos emparientados y procedemos de los mismos troncos de conquistadores y primeros pobladores" (155).

He aquí un Donoso más criollista que esperpéntico, más hispano-criollo que galicista, que concibe un relato local (desde Chile, desde los huasos de Talca) que podría incluirse, en un juego anacrónico, en aquellas Novelas de la Tierra de los años 20, instalando nuestro autor un árbol genealógico que hace crecer a su estirpe desde el mismo suelo americano, cual naturaleza. Ahora bien, esta postulación donosiana surge a propósito de una circunstancia singular: la conjetura que en su genealogía exista una rama judía, que lo situaría en otro origen y conformando otro destino, de carácter diaspórico. Como ya veremos, se dibuja aquí la sombra de Jorge Luis Borges, cuyo apellido portugués -sinónimo de judío en la América colonial-, incluiría acaso un mapa cultural más antiguo o más remoto.

Es extrańo que la identidad se funde aquí sólo en el apellido paterno (los caminos del padre) y no se incluya activamente el apellido Yáńez (los caminos de la madre); no habiendo de este último pesquisa genealógica alguna. Los Yánez sólo existen en la trama en el París de los años veinte y treinta - "el Paris del tío Pilo" (50)-; no arriesgándose a ninguna conjetura mayor: "Tempranos advenedizos muy 
ricos (1900), constituyeron una tribu brillante pero improvisada, culta y francófona gracias a sus largas peregrinaciones por Europa" (26). Al respecto, recordemos que el manuscrito de estas memorias incluía alrededor de cien páginas referidas a la madre de los Yánez, figuras ilustres del siglo XX chileno, que fueron censuradas por el corro familiar, activando la autocensura del autor. Esta mutilación, por cierto, afecta el espíritu de este proyecto, implantando un tupido velo en un libro que pretende ver a su trasluz de modo literal ${ }^{3}$.

Conjeturas: juicios que nos formamos de los hechos, cosas o situaciones por indicios y observaciones. En Donoso las conjeturas se hacen cargo del mundo de las exclusiones, exploran versiones distintas a la oficial; son pintorescas, truculentas, emocionantes. La conjetura es el dispositivo que anima la memoria, que la torna plástica, que permite insertar a su autor en la memoria familiar; un artefacto para la validación subjetiva del sujeto contemporáneo que la crea; un remiendo artificial, un acertijo frente a un enigma: el pasado. En fin, una apuesta del lenguaje para el enigma de los orígenes: "'memoria trucada', pura conjetura azarosa, puro lenguaje" (99).

La conjetura mayor de este libro es una conseja desplegada en tres versiones sobre la historia de Marta Donoso Henríquez, sor Bernarda, monja de clausura en el convento de Las Capuchinas desde 1880, quien nunca se levantó el velo durante las visitas familiares y del presidente, y que el autor siendo nińo (con horror) tuvo la ocasión de escuchar su voz y de recibir sus caricias y adivinar su horrenda figura. Constituye un tercio del libro y bien podría aislarse como un relato independiente. De seguro, este capítulo -una alegoría sobre el hogar talquino: Chile Antiguotendría su correlato en el capítulo censurado sobre los Yáñez, que supuestamente exhibe a una madre viuda recorriendo el territorio nacional en un carromato que funciona como prostíbulo ambulante -otro tipo de alegoría casera-. Memoria conjetural que al parecer la familia leyó de modo literal.

Ahora bien, antes de presentar ese relato, que es una estilización o ejercicio de pastiche de un cuadro de costumbres, que recrea los espacios y atmósferas de la casa patronal, amén de los giros lingüísticos que esconden los valores de una época; quisiéramos referirnos a otras conjeturas menores en que la autoría ensaya guiños sobre la construcción del Yo y de la materia literaria y que tienen como figuras a Marcel Proust, Sigmund Freud y Jorge Luis Borges.

\footnotetext{
${ }^{3}$ Ciertos entretelones sobre la discusión familiar son exhibidos y comentados en la biografía de Pilar Donoso sobre su padre, Correr el tupido velo. La hija escribe: "Todo el escándalo nació a raíz de la insinuación, por supuesto que teñida de fantasía -cosa que esa parte de la familia no pudo entender-, de que la madre de don Eliodoro Yánez, doña María Josefa Ponce de León, ya viuda de Yáńez y apodada, según la leyenda, como la Peta Ponce, había educado a sus seis hijos gracias a una carreta con alegres mujeres que guiaba a distintos pueblos" (369). Pilar se molesta mucho por la claudicación del padre y no entiendo sus razones; sin embargo, nos cuenta, que ya muerto y teniendo ella ahora la facultad de levantar la censura, no lo ha hecho.
} 


\section{PROUST, FREUD, BORGES}

José Donoso le dedica un breve capítulo a su Nana Teresa, una mujer analfabeta que fue traída a la casa capitalina siendo nińa desde uno de los fundos de la familia talquina. Son sólo once páginas, que bien pudieron incluirse como un episodio o una sección dentro de otros capítulos; pero que se aislaron al modo de un homenaje afectivo y culposo a quien lo crió. Sujeto subalterno y local, una zamba iletrada, es supuestamente enaltecida en una conjetura que la emparienta con el mundo de la Belle Ėpoque.

He aquí el tramado. Una trenza: siendo niña, cuando vivía en el fundo maulino, la zambita solía jugar con una niña francesa, Laurie, hija de un ingeniero francés que llegó por una temporada a hacerse cargo de un canal de regadío (el apellido francés ha caído en el olvido). La otra: hojeando una biografía sobre Proust, Pepe Donoso destaca en una foto el personaje de Laure Herman, "una de las grandes horizontales de París de su época" (112), de rostro dulce e irónico. La biografía incluye cartas de alto contenido erótico entre esta dama y Marcel, a quien ella visitaba con frecuencia en su departamento; en fin, Laure sería quizás la única mujer con quien el escritor habría intimado sexualmente. El amarre: siendo que los nombres y edades coinciden, y que la niñita francesa volvió a su tierra natal, bien podría ser... "Es posible conjeturar entonces que la Nana Teresa, gris, humilde y servicial como fue, haya jugado cuando era una nińa pequeña con la que fue una de las mujeres más cultas, elegantes y admiradas de la Europa de su tiempo" (113).

Complejo juego paródico, en que se cruzan el espíritu cosmopolita y lo local, proponiendo equivalencias entre una cocotte y una criada, entre un escritor chileno y uno francés. Más allá de cumplir aquí festivamente el dicho maulino 'Talca, París y Londres' (es decir, es posible para los chilenos 'estar a la altura de las circunstancias'), queremos inquirir en el nudo intersubjetivo de esta conjetura, que puede disponerse en una homología del tipo "A: B :: C: D (es decir: A es a B así como C es a D)".

La relación es entonces la siguiente: Laurie Herman (es a) Marcel Proust (así como) Nana Teresa (es a) Pepe Donoso. Situaciones equivalentes, que permiten el juego de dobles, que incluyen los cuidados del cuerpo ${ }^{4}$.

Doctor Freud. Otra conjetura que la autoría hace para incluirse de modo singular en el álbum familiar tiene como excusa a un tío loco-Cucho-, que habitó por un tiempo la casa de la calle Ejército siendo Pepe y sus hermanos niños y que

\footnotetext{
${ }^{4}$ Las conjeturas y su resolución homológica nos evocan los clásicos esquemas levistraussianos sobre los mitos. Recordemos que Lévi-Strauss define el mito desde el conjunto de sus versiones y despeja su estructura desde una operación homológica, instrumento que permite otorgar una respuesta a un enigma, mediante una mediación (Cf. "La estructura de los mitos"). Frente al enigma de los orígenes, el mundo conjetural donosiano propone diversas variantes que se van resolviendo en cadenas de mediaciones que permiten la trascendencia.
} 
luego fue internado en una Casa de Orates. El dato de inicio es un artículo de la revista Paris-Match que reproduce una foto decimonónica de Charcot examinando a un paciente (cual bestia de zoológico) junto a sus discípulos en un anfiteatro, con un joven vienés judío, Sigmund Freud, observando desde la gradería como único espectador melancólico marginal. Tanto la foto como el texto que la comenta en la revista actúan como un disparador para elucubrar sobre una posible relación sobre ese gran relato (la fundación del psicoanálisis) y el relato menor chileno. Y también, la oportunidad para que el autor aparezca en la foto (en la foto de la Historia), o sea, logre una filiación (artificial, espúrea, pero no por ello menos material e identitaria) con los grandes discursos y sus protagonistas.

Luego de una serie de especulaciones con los pocos datos con que se cuenta, el autor nos propone "una conjetura seductora" (133), basada en un intrincado tramado de posibles coincidencias. El tío energúmeno Cucho Concha sería el enfermo mental de la foto, habiendo sido paciente de Charcot y luego de Freud (puesto que su padre, el prestigioso urólogo Agustín Concha conoció a éste último durante su estadía en París). Poniéndose en la foto, José Donoso nos indica que en el presente se está haciendo un psicoanálisis y sentencia: "Debajo de todas mis fantasías sentí la seguridad de que era yo mismo a quien ese científico y sus discípulos vejaban” (134).

Nuevamente, la homología es muy transparente: el tío Cucho (es a) Sigmund Freud (así como) Pepe Donoso (es a) su psicoanalista. Así, siniestramente, la máquina vejatoria de la ciencia de la psiquis aparece interviniendo en dos tiempos distintos a un mismo cuerpo familiar, permitiendo al autor rescatar una figura marginal (un bruto), aunándose con él desde el dolor síquico.

Notemos que en las dos conjeturas anteriores se rescatan para el álbum familiar figuras vinculadas a lo bajo, lo subordinado, lo excluido: una zamba analfabeta que lo crió (lo manoseó) y un enfermo mental con ataques de ira que está al cuidado de un exboxeador (¿un alter del siquiatra?) que lo termina asesinando con una última y feroz golpiza.

Hay otra conjetura, que es primero propuesta y luego descartada, que lo liga a otra tribu (el pueblo errante, los judíos portugueses en América); pero que muy especialmente, le permite medirse y confrontarse con un referente obligado de las letras latinoamericanas: Jorge Luis Borges 5

\footnotetext{
${ }^{5}$ En el transcurso del libro existe cierto esfuerzo didáctico de la autoría para indicar qué datos, nombres de personajes y situaciones tienen un referente literal en la genealogía, generándose una gradación desde el dato real, lo verosímil, hasta lo descabellado. Lo sentimos como un pie forzado y conjeturamos se debe a las censuras familiares que sufrió el manuscrito; lo cual habría llevado a Pepe Donoso a dar explicaciones y realizar desvíos que obviamente empobrecen el proyecto de una memoria tribal despertada y animada por la inventiva.
} 
Ahora no es una imagen fotográfica lo que lo mueve a una conjetura; sino un encuentro personal ocurrido en un contexto literario. Un hombre de barba negra, "de aspecto sacerdotal" se acerca a Pepe en la Feria Internacional del Libro de Buenos Aires en 1988, presentándose como un posible pariente: su nombre es José Donoso Ergas. "-soy judío sefardita de Esmirna -me dijo-, y mi padre es rabino. Mis tíos y nosotros tenemos aquí en Buenos Aires una fábrica de ropa de algodón de punto, y una tienda que vende al menudeo en el Once" (151-152). A continuación lo invita a conocer a su familia ("Mis mayores quisieran conocerlo", 151), el escritor acepta; pero finalmente el encuentro es frustrada por el azar y la distracción.

Donoso juega con esta idea y cual personaje borgeano, imagina posibles escenarios, para finalmente descartarlos, reconociéndose en el corro americano, cuyo antecedente se alojaría en las tierras de Extremadura: “¿Donoso de Esmirna? ¿De Asia Menor? ¿De la patria de Homero, donde nacieron, o por lo menos fraguaron, La Ilíada y La Odisea? ¡Qué idea más descabellada!” (154).

Aún cuando el encuentro sea verdadero y que la conjetura permite vincularlo a la historia universal vivida desde su marginalidad diaspórica; nosotros conjeturamos que está diseńado como una cita borgeana. En principio, las marcas de un encuentro fortuito fuera del tiempo de un sujeto con su doble pertenecen a la tradición de la literatura fantástica, no siendo privativas sólo de los relatos de Borges. Aún así, atendiendo a algunos detalles de este encuentro en la biblioteca (degradada) de las Ferias de Libros, intuimos que es una escena borgeana, puesto que evoca la atmósfera, el tono y las situaciones de muchos de sus relatos. Y si tuviéramos que elegir solo uno, se nos viene a la mente el cuento "El jardín de senderos que se bifurcan", aquel en que un espía oriental, Yu Tsun, va al encuentro de un absoluto desconocido: Stephen Albert. Este desconocido, escogido solo por su nombre propio, resulta ser un sinólogo inglés que vive en una biblioteca que está en el centro de un jardín chino, que otorga una respuesta posible al enigma de los orígenes de nuestro espía. Es como si el destino llamara a la puerta: un Donoso al encuentro de su origen sefardita y Yu Tsun descubriendo un misterio ancestral. Hay detalles de composición; por ejemplo, la fisonomía contradictoria de los personajes: Donoso Ergas semejando un intelectual a pesar del oro en sus dedos y muñecas, cual matón de barrio; el sinólogo inglés, que tiene algo de sacerdote y de marino. Además, el referente chino, situado en el cuento de Borges en laberintos y bibliotecas con libros orientales es retomado aquí en un comentario paródico sobre el nombre de la traductora del chino de las obras de José Donoso, cuyo apellido 'Douan' es muy común en su lengua (así como lo es 'Donoso' en español; nótese, para mayor redundancia, que ambos apellidos se parecen).

Débil conjetura, se dirá; débiles eslabones de una cadena significante que está por configurarse. La alusión a Borges (como escritor, como artífice de ficciones) se hace evidente en la misma escena del encuentro, cuando al oír la invitación ("Mis 
mayores quisieran conocerlo"), Pepe nos indica: "Era una palabra ['mayores'] que yo sólo recordaba en algún texto de Borges, escrita, me pareció, con una reverencia que no es frecuente entre los Donoso que yo conozco" (151).

El poema recordado es "Los Borges", cuyos primeros versos son: "Nada o muy poco sé de mis mayores / Portugueses. Los Borges: vaga gente / que prosigue en mi carne, oscuramente, / sus hábitos, rigores y temores" (831). José Donoso considera que el tono reverencial borgeano no es el suyo (y por extensión, toda su poética). Lo sorprendente es que recuerde este poema sobre los antepasados y no el paradigmático, que Borges le dedica a Francisco Laprida, conjeturando sus últimos pensamientos antes de morir ${ }^{6}$. Nos referimos a "Poema conjetural", en el cual leemos: "Yo que anhelé ser otro, ser un hombre / de sentencias, de libros, de dictámenes, / a cielo abierto yaceré entre ciénagas; / pero me endiosa el pecho inexplicable / un júbilo secreto. Al fin me encuentro / con mi destino sudamericano" (867).

Donoso se inscribe en la tradición de la celebración de la genealogía americana, que tiene en Borges a un ineludible representante. Pues si bien es cierto que Borges tendría antecedentes diaspóricos (y quizás ello lo lleve a una literatura anclada en lo remoto), también tiene una rama criolla, con antepasados heroicos en tierras argentinas (no sólo de Esmirna viene...). Y también se ha inscrito en el ciclo americano, a través de la figuración del binomio 'civilización / barbarie'.

Pero lo esencial en la alusión a Borges es el acto de nombrar metonímicamente el "Poema conjetural" y en este título, la palabra conjetural, que constituye uno de los sustantivos del título del libro de Donoso. La conjetura es un procedimiento privilegiado en el sistema borgeano: un modo poético de intervenir lo real para alterarlo, un modo de tergiversar la historia oficial, un artefacto que convierte lo dado en una concreción entre otras posibles. Cuando Albert (cuyo nombre esconde la relatividad) despeja el enigma de una novela oriental que simula el infinito, nos lo comunica con las siguientes palabras: "Al cabo de más cien años, los pormenores son irrecuperables, pero no es difícil conjeturar lo que sucedió" (105).

En efecto, todas las historias borgeanas son conjeturales y también sus personajes. Conjeturo que Donoso se siente deudor de las ficciones borgeanas, que las roba, y que deja las huellas de su admirada envidia. En el panteón americano, Pepe se instala haciendo un guiño al pequeño Georgie; más anglosajón que él pero igualmente mestizo.

Como colofón, recordemos que la novela Respiración artificial de Ricardo Piglia - una reflexión sobre la constitución del discurso de la Historia desde la autocensura, en la cual la figuración borgeana juega un rol trascendente- ensaya

\footnotetext{
${ }^{6}$ Recordemos el epígrafe del "Poema conjetural", donde se enuncia la identidad americana desde la urdimbre 'civilización/barbarie': "El doctor Francisco Laprida, asesinado el día 22 de setiembre de 1829 por los montoneros de Aldao, piensa antes de morir: " (867).
} 
encuentros conjeturales de personajes que remueven nuestros juicios; por ejemplo, las posibles conversaciones de Kafka con Hitler en los cafés berlineses previo a la Gran Guerra.

Como ya hemos dicho, la genealogía materna casi no aparece explorada (está solo el capítulo parisino). Existe, eso sí, en los inicios del libro un episodio central donde se evoca una visita de la madre a su hijo Pepe al poblado de Vallvidrera, cercano a Barcelona, para ayudar en los cuidados maternos a la familia (María Pilar está enferma y necesita ayuda con Pilarcita de solo dos años). Es una evocación, a quince ańos de la muerte de la madre.

El suceso relatado es extraño y conlleva el peso de la pérdida. Pepe, hombre cuarentón, sigue los pasos de su madre en sus incursiones diarias por las Ramblas y la Plaza Real de la gran ciudad catalana y cual voyeur espía fascinado sus encuentros con un joven marginal: "El negro era feroz, largo, flaco, una sombra inmensa, las facciones marcadas con crueles cicatrices tribales" (31).

Un encuentro con otra tribu, más elemental. La autoría conjetura con nosotros el sentido de esos diálogos (que no escuchamos), interpretando la gestualidad de ambos. Los paseos se repiten y finalmente hay una escena de despedida: "-Mammy...mammy...adieu, mammy..."; a lo cual ella responde: "Sam...Sam..." (33). El misterio se despeja ese día cuando la mamá (suponemos de casi setenta años) vuelve a la casa y se confía a María Pilar (no en un hijo, como aclara Pepe): "Se lo contó todo a borbotones. Sam, dijo, era un negro francófono de Senegal, por eso sus piernas tan largas, sus brazos interminables, su cabeza pequeña y elegante, su talle enjuto como el de un insecto" (34).

El episodio es uno de los más logrados del libro, por su intransitividad. Aun cuando uno se entusiasme por una interpretación, pronto se revela mezquina ante la contención emocional de todo el pasaje. Indicar que Sam (más...) es el hijo que no tuvo, un hombre niño ("un hombre hecho y derecho", 32); un juguete coleccionable ("su cabeza pequeña y elegante, su talle enjuto como el de un insecto"), un fetiche, el que ocupa el lugar de Pepe; es una lectura acaso ingenua y por ello prescindible. Indicar que Sam se sitúa en la serie de la negritud, junto a la zamba (la Nana Teresa) y a Custodio (un negrito esclavo de la casa colonial) señalando la marginalidad como una puerta de acceso a lo humano; parece una lectura más acotada y que permite la asociación con la homología de los cuidados de la Nana Teresa con el niño de la crianza.

Lo fundamental es que el autor realiza un homenaje a la memoria de su madre, otorgándole en su evocación una libertad de tránsito, de peregrinaje, que estaba en su ser. El abrazo de lo marginal la purifica, la sexualiza, la incluye como dadora de una imagen a un hijo que deambula por la genealogía familiar en busca de sustento concreto y sensible. 


\section{HISTORIA CONJETURAL DE LA CASA TALQUINA}

Retomemos uno de los pilares de este libro, referido a la historial conjetural de Marta Donoso Henríquez, sor Bernarda, expuesta en tres sabrosas versiones, concebidas como alegorías nacionales. Una imagen clara de la tribu aparece condensada en la casa familiar de Talca de fines del siglo XIX, ubicada al frente de la Plaza de Armas. Si el autor logra animar esa casona de cuatro patios (el de visitas, de las niñas, de los hermanos y de los guachos), si ensaya sus corros secretos, si hilvana rumores y despojos; entonces estará conviviendo con su estirpe.

A un siglo de distancia, cuando ya no hay testigos (sólo murmullos), cuando hay un enigma incluso en la crónica familiar (¿por qué sor Bernarda nunca se quita el velo, ni siquiera ante sus seres más queridos, ni siquiera ante el presidente Federico Errázuriz Echaurren?), cuando el orden familiar se constituye desde la imagen del tupido velo (la casa talquina como una casa tapiada, una casa de clausura); entonces se debe componer una conjetura con los datos dispersos y despojos de la memoria, siendo acomodado luego como medallón.

Remedando el ejercicio de un arqueólogo, José Donoso se instala en un espacio neutro (en la actualidad, esa casa opera como un feo conjunto de dependencias arrendadas a diversas reparticiones públicas, guardando todavía un par de debilitadas columnas con la letra $\mathrm{D}$ en su capitel) y lo reanima acudiendo a un lenguaje que remeda la conseja (cuento de sabor antiguo) y el cuadro de costumbres. Es un relato estilizado, un pastiche del criollismo intervenido juguetonamente, con breves escarceos con lo grotesco. Léase por ejemplo este retocado cuadro: "Aún con el brasero encendido en la salita, la familia permanecía con sus largos abrigos puestos, y al retirarse a sus dormitorios las siluetas de las mujeres, enfundadas en chales y más chales, eran negras y de forma incierta como berenjenas, taconeando muy aprisa para encerrarse en sus cuartos" $(198)^{7}$.

Donoso diseña tres versiones para el misterio del velo, teniendo como marco la vida pública de la época. Al respecto, el artífice comenta: "Sigue pareciéndome curioso, sin embargo, que para construir esos personajes de vidas tan privadas me sea necesario echar mano de las grandes pasiones públicas, económicas y sociales que conmovieron esa época" (187). Una historia familiar que es emblema de la

\footnotetext{
${ }^{7}$ En realidad, todo el capítulo está plagado de descripciones campestres escritas como remedando una literatura realista criolla. Así, al describir las faenas del patio de los guachos -las vísceras de la casa, se nos dice- se nos pinta la siguiente escena: "Las lavanderas enjuagaban la ropa en enormes artesas de lavaza celeste, almidonaban y planchaban, otras mujeres, arrodilladas junto a sus piedras, molían la chuchoca enrojecida por el solazo de los tejados; los chiquillos bruñían los bronces de la calesa y del coche-trompa; los hombres limpiaban y cargaban las lámparas de carburo y las dejaban en escuadrones en el suelo de los corredores, tiñendo el aire con su peculiar fetidez hasta que Custodio acudía a llevárselas 'para afuera”" (192-193).
} 
nación, la pesquisa de un escudo de armas en el edificio chileno (desde que fue Reino hasta su actual fachada semiderruida).

La primera conjetura descorre el velo conservador de la matriarca de la casa: la joven Marta quiere sacrificar su vida por su hermana Eugenia (viuda que huyó del hogar talquino con sus dos hijos junto al Gringo Barrow, apareciendo más tarde en San Francisco); quiere ser monja y dedicarse a hacer el bien, practicando la caridad. Pero la matriarca (la Mamita) la obliga a ser monja de clausura (y no 'puertas afuera'). Como gesto de rebelión, nunca más se quita el velo ante la visita familiar o presidencial.

La versión liberal-conservadora propone que Marta expía el pecado de su hermana, encerrándose voluntariamente en el convento de Las Capuchinas y no se levanta el velo en la visita de la familia y del presidente, pues sustentan el pensamiento liberal, propio de masones (gente del demonio).

La tercera versión surge, según confesión del autor, nueve años después y constituye, las más donosiana. Mientras que las anteriores le permitían una visita graciosa a tiempos ya idos; esta última le otorga un sello singular, propio de su obra literaria: ahora será el juego de la identidad robada, suplantada, travestida. En esta conjetura, la joven Marta no acepta ser forzada a la clausura en el convento de Las Capuchinas y se suicida, siendo suplantada por la Mariconilla, criada de la casa, quien toma su lugar en plena potestad. A instancia de la Mamita, es enterrada impíamente cual envoltorio vacío cerca de un basural (en una escena que evoca la desaparición definitiva del Mudito en las páginas finales de El obsceno pájaro de la noche). De pasada, Pepe insiste que Mariconilla es el nombre verdadero de una sirvienta de esa casa antigua y que en ese entonces no tenía las connotaciones de ahora. Ella (la otra) muere feliz y bien atendida en el convento de clausura de Las Capuchinas situada en ese entonces en calle Rosas abajo, hoy Lira.

Esta versión se conecta con la conjetura sobre el nombre y la identidad del primer Donoso llegado a Chile: un cura Donoso moribundo mandando a buscar a la Madre Patria a un sobrino suyo (¿̨realmente su sobrino?) y éste en tierras del Reino de Chile, cambiando de nombre, adoptando el de Francisco Donoso Pajuelo Cerrudo, heredando los bienes del tío. ¿La suplantación en el mismo origen? ¿La pintoresca -que no grotesca ominosa- transgresión moral, normal en la época, que inaugura una genealogía que Pepe Donoso la sigue hasta nuestros días?

Estas historias conjeturales se sostienen gracias al gesto evocador de un lenguaje que parece pegado a esos tiempos. Son historias repasadas en sepia, posibles guiones puestos a fotos antiguas de banquetes familiares en honor de figuras públicas o a álbumes comprados en las calles parisinas (acción meteca, de sudamericanos tratando de entreverarse en una historia y genealogía de mayor prestigio), con su sinnúmero de rostros en pose, esperando a ser adivinados. 


\section{REFERENCIAS}

Borges, Jorge Luis. Obras completas. Buenos Aires: Emecé, 1974.

Donoso, José. Conjeturas sobre la memoria de mi tribu. Santiago de Chile: Alfaguara, 1996.

Donoso, Pilar. Correr el tupido velo. Santiago de Chile: Alfaguara, 2009.

Edwards, Jorge. Los círculos morados. Memorias I. Santiago de Chile: Lumen, 2012.

Lévi-Strauss, Claude. "La estructura de los mitos", Antropología estructural. Buenos Aires: Eudeba, (1970): 183-210.

Piglia, Ricardo. Respiración artificial. Buenos Aires: Sudamericana, 1980. 